\title{
Health economic evaluation of patients with sepsis after gastrointestinal tumor surgery-a cost consequences analysis in China
}

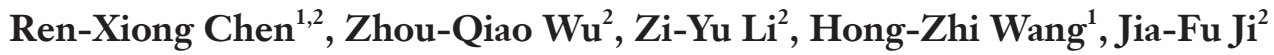 \\ ${ }^{1} \mathrm{ICU},{ }^{2}$ Gastrointestinal Cancer Center, Key Laboratory of Carcinogenesis and Translational Research (Ministry of Education/Beijing), Peking \\ University Cancer Hospital \& Institute, Beijing, China \\ Contributions: (I) Conception and design: RX Chen, HZ Wang, JF Ji; (II) Administrative support: RX Chen, HZ Wang, JF Ji; (III) Provision of study \\ materials or patients: ZQ Wu, ZY Li; (IV) Collection and assembly of data: RX Chen, ZQ Wu, ZY Li; (V) Data analysis and interpretation: RX \\ Chen, HZ Wang, JF Ji; (VI) Manuscript writing: All authors; (VII) Final approval of manuscript: All authors. \\ Correspondence to: Hong-Zhi Wang; Jia-Fu Ji. Peking University Cancer Hospital \& Institute, No. 52 of Fucheng Road, Haidian District, Beijing \\ 100142, China. Email: wanghz58@sina.com; Jiafuj@hotmail.com.
}

\begin{abstract}
Background: The purpose of this study was to evaluate the health economics of patients with sepsis after gastrointestinal tumor operation in ICU.

Methods: This case-control study used 1:1 propensity-score (PS) matched method and patients were matched according to tumor type, age and gender. The study group was composed of 181 patients with sepsis after operation of gastrointestinal tumor in ICU, while the control group was composed of 181 patients without sepsis after operation of gastrointestinal tumor. The medical expenses and length of stay in the hospital of these patients were analyzed.

Results: The median of the total hospitalization cost for the study group was $\$ 26,038$, which was 1.7 times of the control group $(\mathrm{P}<0.001)$. The costs of drugs, laboratory test, examination, treatment, operation, anesthesia, materials, ward and other costs in the study group were higher than those in the control group $(\mathrm{P}<0.001)$. The median length of stay in the hospital in the study group was 26 days, which were 12 days longer than that of the control group $(\mathrm{P}<0.001)$. However, there was no significant difference in daily average cost between the two groups $(\mathrm{P}=0.103)$.
\end{abstract}

Conclusions: In ICU, patients with sepsis after operation of gastrointestinal tumor increased the cost of hospitalization and prolonged the length of stay in the hospital than those without sepsis.

Keywords: Health economic evaluation; sepsis; gastrointestinal tumor

Submitted Jun 22, 2020. Accepted for publication Aug 18, 2020.

doi: 10.21037/jgo-20-242

View this article at: http://dx.doi.org/10.21037/jgo-20-242

\section{Introduction}

Sepsis was a global problem, which had become one of the main reasons that affected the safety of patients and increased medical costs (1). It was estimated that there were 31.5 million patients with sepsis every year all over the world, and about 5.3 million patients died every year (2). In China, there were 5.68 million patients with sepsis every year (3). To our knowledge, inducing factors of sepsis included community-acquired infection and nosocomial infection, and millions of people were affected by nosocomial infection every year around the world (4). In the United States, the cost of hospitalization for sepsis became the fourth largest, with an annual cost of 23.7 billion US dollars (5). However, the direct economic loss caused by sepsis in China was not obscure. A 1:1 matched case-control study was used to evaluate the economic loss caused by sepsis, to provide an evidence-based basis for control and prevention of sepsis. 


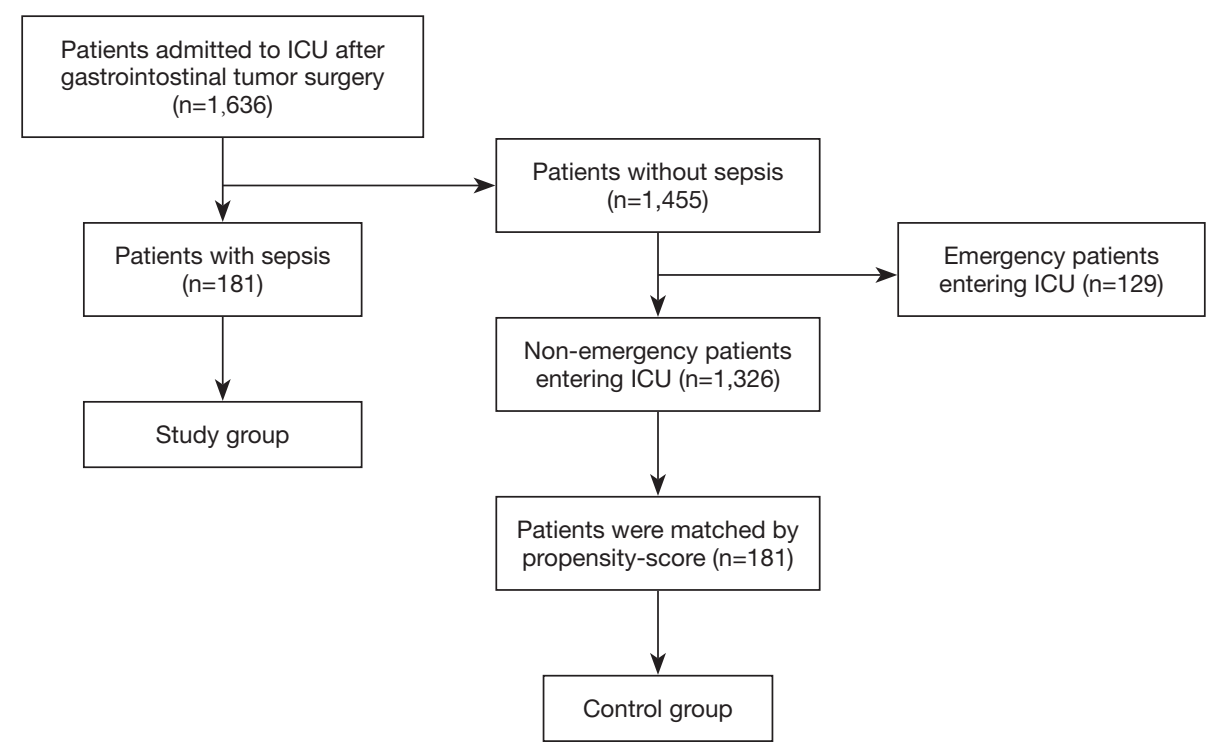

Figure 1 Flow diagrams of studying selection process.

We present the following article in accordance with the MDAR reporting checklist (available at http://dx.doi. org/10.21037/jgo-20-242).

\section{Methods}

\section{Study population}

From January 2015 to December 2019, 1,636 patients were admitted to the ICU after gastrointestinal tumor surgery in the gastrointestinal cancer center of Peking University Cancer Hospital. The study was conducted in accordance with the Declaration of Helsinki (as revised in 2013). The study was approved by the Institutional Review Board of Peking University Cancer Hospital (No. 2020KT) and informed consent was taken from all the patients or their next of kin. One hundred eighty-one patients with sepsis were enrolled in the study group. According to the tumor type, age and gender, we did 1:1 greedy matching using a caliper of 0.1 standard deviations of the propensity-score (PS) to identify clinically similar matched controls for each patient. The control group was composed of 181 patients who were admitted for selective gastrointestinal tumor surgery at the same time. See Figure 1 for the screening flow. We collected the cost of hospitalization and length of stay, and evaluated the health economics of patients with sepsis. Considering the impact of inflation and cost changes, the conversion between RMB and US dollar was based on the average value of each month's exchange rate calculated by the People's Bank of China from January 2015 to December 2019.

\section{Statistical analysis}

The normal distribution continuous variables were described by mean \pm standard deviation, and t-test was used for statistical analysis. The non-normal continuous variables were described by median and quartile (P25, p75), and were analyzed by Mann-Whitney U test. Chi-square test was used to analyze categorical variables. Statistical analyses were carried out using SPSS version 24.0 and $\mathrm{P}$ values less than 0.05 (two-tailed) were considered significant.

\section{Results}

The 90 -day all-cause mortality rate was $11.1 \%$ in the study group, while $1.1 \%$ in the control group. The baseline characteristics of patients in the two groups were shown in Table 1. There was no significant difference in age, tumor type, body mass index (BMI) and length of operation time between the two groups except for sex and coexisting conditions between the two groups. Coexisting conditions were shown in the Table S1.

\section{Direct economic loss caused by sepsis}

The median of the total hospitalization expenses of the 
Table 1 Baseline characteristics of patients in the two groups

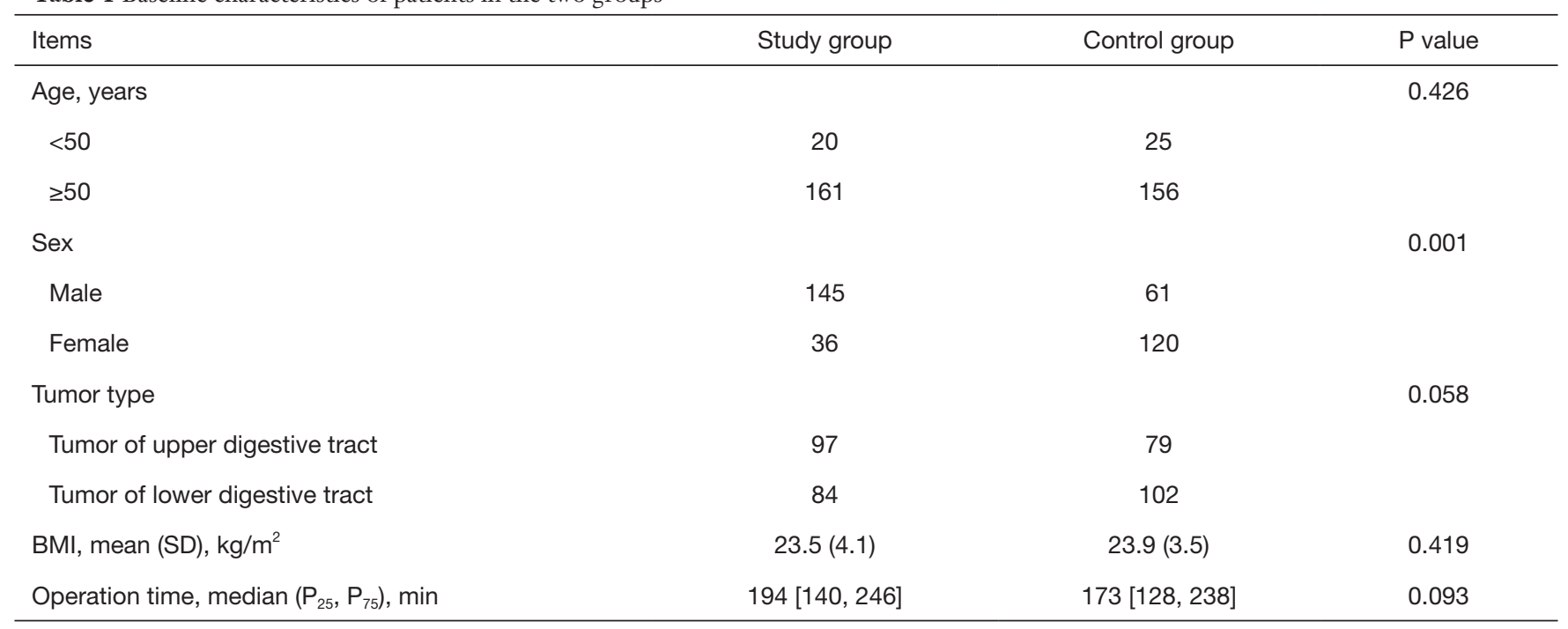

Table 2 Costs between the two groups

\begin{tabular}{|c|c|c|c|c|}
\hline Cost category & Study group, \$ & Control group, \$ & $Z$ value & $P$ value \\
\hline Drugs & $7,353[5,039,12,218]$ & $3,222[2,247,4,479]$ & -11.653 & $<0.001$ \\
\hline Examination & $934[536,1,249]$ & $503[308,848]$ & -6.248 & $<0.001$ \\
\hline Treatment & $2,635[1,611,4,061]$ & $1,157[797,1,481]$ & -10.847 & $<0.001$ \\
\hline Anesthesia & $143[81,172]$ & $78[68,94]$ & -8.077 & $<0.001$ \\
\hline Materials & $10,432[7,738,13,320]$ & $8,313[6,892,10,093]$ & -5.254 & $<0.001$ \\
\hline Ward & $217[133,413]$ & $100[73,156]$ & -8.452 & $<0.001$ \\
\hline Other costs & $632[339,1,219]$ & $204[54,353]$ & -10.699 & $<0.001$ \\
\hline
\end{tabular}

study group was $\$ 26,038$, while the control group was $\$ 15,131$. The cost of the study group was 0.7 times higher than that in the control group, with an average of $\$ 10,907$ for each case. The difference between the two groups was statistically significant $(Z=-10.662, P<0.001)$. The costs of drugs, laboratory test, examination, treatment, operation, anesthesia, materials, ward and other costs in the study group were higher than those in the control group $(\mathrm{P}<0.001)$. Among the hospitalization cost, the cost of drugs increased the highest, followed by the cost of materials and treatment. See Table 2 for details.

\section{The median length of stay in the bospital}

The median length of stay was $26[18,42]$ days in the study group and 14 [11, 19] days in the control group. The median length of stay in the study group was 12 days longer than that of the control group $(Z=-8.985, P<0.001)$.

\section{The average daily cost of the two groups}

The average daily cost was $\$ 957$ [774, 1,235] in the study group, and $\$ 1,019$ [819, 1,298] in the control group. There was no significant difference between the two groups 
$(\mathrm{Z}=-1.629, \mathrm{P}=0.103)$.

\section{Discussion}

Twenty-eight years ago, Bone et al. (6) reported a consensus document that provided the initial definition of sepsis. With people's understanding of sepsis, a new definition of sepsis was made in recent years. That was life-threatening organ dysfunction caused by the host's maladjusted response to infection, which was manifested in the sepsis-related organ failure score greater than or equal to 2 points (7). The study group in our study was screened out by the new definition. Sepsis was associated with high mortality, and the economic loss caused by sepsis would bring a great financial burden to the family members and the society. At present, there are many foreign reports on the health economics evaluation of sepsis-related interventions (8-12), however, few domestic reports in China.

This study showed that the costs of drugs, laboratory test, examination, treatment, operation, anesthesia, materials, ward, other costs and total hospitalization costs in the study group were higher than those in the control group. In addition to increasing the cost of hospitalization, sepsis also extended the length of stay in the hospital and affected the turnover of hospital wards. In addition, the actual losses of death, work delay, family care and other indirect costs caused by sepsis were greater. However, in this study, the difference in patients' daily average cost between the two groups was not statistically significant, which might be related to the higher cost of drugs and consumables in the first few days of operation.

The evaluation of health economics for critical patients was mainly based on the study of cost-effectiveness, costutility, cost-benefit and cost-minimization (13-15). By analyzing the health economics of patients with sepsis, it can directly reflect the importance of sepsis management, sepsis prevention, reducing the incidence of sepsis, saving medical resources, reducing the cost of single disease treatment, reducing the economic burden for patients and bringing reputation and benefits to the hospital. With the deepening of the reform of the medical insurance system in China, the medical insurance payment methods such as single disease payment and total prepayment will be gradually improved, and the excess payment will be partially or completely borne by the hospital, which will also bring challenges. Therefore, it will bring significant economic and social value to carry out the research on cost-effectiveness, cost-utility and costbenefit of sepsis and integrate the economic evaluation of sepsis health into the daily management.

\section{Limitations}

Certainly, this study has some limitations. First, the control group of this study was matched from the patients entering ICU with more chronic diseases than the study group, and more chronic diseases than the general population; however, this did not affect our conclusions. Second, the gender difference between the matched control group and the study group was obvious, but we had observed that gender had the little effect on the cost in clinical practice, so we thought that gender had the little effect on the conclusion. Third, the object of this study was the patients with sepsis who entered ICU after the operation of gastrointestinal tumor. Whether the conclusion can be extended to all sepsis patients need more researches to confirm. Finally, this study is a retrospective study and unable to evaluate the cost of the interventions. We hope that there will be more prospective studies to evaluate the interventions in health economics in the future in China.

\section{Conclusions}

In ICU, patients with sepsis after operation of gastrointestinal tumor increased the cost of hospitalization and prolonged the length of stay in the hospital than those without sepsis.

\section{Acknowledgments}

Funding: The study was funded by B. Braun Anaesthesia Science Research Foundation (BBFD-2015-16).

\section{Footnote}

Reporting Checklist: The authors have completed the MDAR reporting checklist. Available at http://dx.doi.org/10.21037/ jgo-20-242

Data Sharing Statement: Available at http://dx.doi. org/10.21037/jgo-20-242

Peer Review File: Available at http://dx.doi.org/10.21037/ jgo-20-242

Conflicts of Interest: All authors have completed the ICMJE uniform disclosure form (available at http://dx.doi. 
org/10.21037/jgo-20-242). The authors have no conflicts of interest to declare.

Ethical Statement: The authors are accountable for all aspects of the work in ensuring that questions related to the accuracy or integrity of any part of the work are appropriately investigated and resolved. The study was conducted in accordance with the Declaration of Helsinki (as revised in 2013). The study was approved by the Institutional Review Board of Peking University Cancer Hospital (No. 2020KT) and informed consent was taken from all the patients or their next of kin.

Open Access Statement: This is an Open Access article distributed in accordance with the Creative Commons Attribution-NonCommercial-NoDerivs 4.0 International License (CC BY-NC-ND 4.0), which permits the noncommercial replication and distribution of the article with the strict proviso that no changes or edits are made and the original work is properly cited (including links to both the formal publication through the relevant DOI and the license). See: https://creativecommons.org/licenses/by-nc-nd/4.0/.

\section{References}

1. Reinhart K, Daniels R, Kissoon N, et al. Recognizing sepsis as a global health priority - a WHO resolution. $\mathrm{N}$ Engl J Med 2017;377:414-7.

2. Fleischmann C, Scherag A, Adhikari NK, et al. Assessment of Global Incidence and Mortality of Hospital-treated Sepsis. Current Estimates and Limitations. Am J Respir Crit Care Med 2016;193:259-72.

3. Liao X, Du B, Lu M, et al. Current epidemiology of sepsis in mainland China. Ann Transl Med 2016;4:324.

4. Organization WHO. Report on the burden of endemic health care-associated infection worldwide. World Health Organization 2011.

5. Torio CM, Moore BJ. National inpatient hospital costs: the most expensive conditions by payer, 2013. HCUP

Cite this article as: Chen $\mathrm{RX}, \mathrm{Wu} \mathrm{ZQ}, \mathrm{Li} \mathrm{ZY}$, Wang HZ, Ji JF. Health economic evaluation of patients with sepsis after gastrointestinal tumor surgery-a cost consequences analysis in China. J Gastrointest Oncol 2020;11(5):894-898. doi: 10.21037/ jgo-20-242
Statistical Brief \#204. Rockville, MD: Agency for Healthcare Research and Quality, 2016.

6. Bone RC, Balk RA, Cerra FB, et al. Definitions for sepsis and organ failure and guidelines for the use of innovative therapies in sepsis. The ACCP/SCCM Consensus Conference Committee. Chest 1992;101:1644-55.

7. Singer M, Deutschman CS, Seymour CW, et al. The Third International Consensus Definitions for Sepsis and Septic Shock (Sepsis-3). JAMA 2016;315:801-10.

8. Farrugia A, Bansal M, Balboni S, et al. Choice of Fluids in Severe Septic Patients - A Cost-effectiveness Analysis Informed by Recent Clinical Trials. Rev Recent Clin Trials 2014;9:21-30.

9. Kip MM, Kusters R, IJzerman MJ, et al. A PCT algorithm for discontinuation of antibiotic therapy is a cost-effective way to reduce antibiotic exposure in adult intensive care patients with sepsis. J Med Econ 2015;18:944-53.

10. Kip MMA, van Oers JA, Shajiei A, et al. Cost-effectiveness of procalcitonin testing to guide antibiotic treatment duration in critically ill patients: results from a randomised controlled multicentre trial in the Netherlands. Crit Care 2018;22:293.

11. Tsaganos T, Raftogiannis M, Pratikaki M, et al. Clarithromycin Leads to Long-Term Survival and Cost Benefit in Ventilator-Associated Pneumonia and Sepsis. Antimicrob Agents Chemother 2016;60:3640-6.

12. PRISM Investigators, Rowan KM, Angus DC, et al. Early, Goal-Directed Therapy for Septic Shock - A Patient-Level Meta-Analysis. N Engl J Med 2017;376:2223-34.

13. Alsarraf AA, Fowler R. Health, economic evaluation, and critical care. J Crit Care 2005;20:194-7.

14. Wilcox ME, Vaughan K, Chong CAKY, et al. CostEffectiveness Studies in the ICU: A Systematic Review. Crit Care Med 2019;47:1011-7.

15. Higgins AM, Brooker JE, Mackie M, et al. Health economic evaluations of sepsis interventions in critically ill adult patients: a systematic review. J Intensive Care 2020;8:5. 
Supplementary

Table S1 Comparison of coexisting diseases in two groups

\begin{tabular}{lccc}
\hline Coexisting disease & Study group & Control group & P value \\
\hline Hypertension & 64 & 93 & 0.002 \\
Yes & 117 & 88 & \\
No & & & 0.024 \\
Diabetes & 32 & 50 & \\
Yes & 149 & 131 & $<0.001$ \\
No & 17 & 50 & \\
Coronary heart disease & 164 & 131 & $<0.001$ \\
Yes & & & \\
No & 9 & 31 & \\
Arrhythmia & 172 & 150 & \\
Yes & & & \\
No & & & \\
\hline
\end{tabular}

